\title{
Mapping of Cotton-Melon Aphid Resistance in Melon
}

\author{
John Klingler \\ Department of Plant Sciences, Forbes Building Room 303, University of Arizona, Tucson, AZ85721-0036
}

Irina Kovalski and Leah Silberstein

Department of Life Science, Bar-Ilan University, Ramat-Gan 52900, Israel

Gary A. Thompson ${ }^{1}$
Department of Plant Sciences, Forbes Building Room 303, University of Arizona, Tucson, AZ85721-0036

Rafael Perl-Treves

Department of Life Science, Bar-Ilan University, Ramat-Gan 52900, Israel

AdDitional INDEX wORDS. Aphis gossypii, Cucumis melo, insect, phloem, NBS-LRR

\begin{abstract}
Resistance to cotton-melon aphid (Aphis gossypii Glover) segregated as a single dominant gene in a melon (Cucumis melo L.) mapping population derived from the cross 'Top Mark' X PI 414723. Sixty-four $F_{2}$-derived $F_{3}$ families were used to map the aphid resistance locus, Vat, with respect to randomly amplified polymorphic DNA (RAPD) and restriction fragment length polymorphism (RFLP) markers. RFLP markers NBS-2 and AC-39 flanked Vat at distances of $3.1 \mathrm{cM}$ and $6.4 \mathrm{cM}$, respectively. NBS-2 is homologous to the nucleotide binding site-leucine-rich repeat (NBS-LRR) superfamily of plant resistance genes. Another homolog of this superfamily, NBS-5, was positioned $\approx 16.8 \mathrm{cM}$ from Vat, raising the possibility that $V$ at resides in a cluster of NBS-LRR paralogs. RFLP marker AC-8, which has similarity to plant lipoxygenases, was positioned at $\approx 5.5 \mathrm{cM}$ from $\mathrm{Vat}$. Monogenic resistance to $A$. gossypii has been identified in two sources of melon germplasm, Indian accession PI 371795 (progenitor of PI 414723) and Korean accession PI 161375. To test for an allelic relation between the genes controlling aphid resistance in these two distinct germplasm sources, melon plants of a backcross population from a cross between two resistant lines having Indian- or Korean-derived resistance were infested with aphids. At least 90 out of 92 segregating progeny were aphid resistant, suggesting that the same resistance gene, Vat, is present in both sources of melon germplasm.
\end{abstract}

The cotton-melon aphid (Aphis gossypii) is among the most destructive insects to agriculture in the United States and abroad (Slosser et al., 1989). It has an expansive host range and lowers crop yields by transmitting over 50 plant viruses and extracting plant nutrients (Blackman and Eastop, 1984). The insect also covers its host with honeydew, which supports the growth of fungi that stain harvested plant parts and interfere with light absorption. In addition to harming field crops, A. gossypii causes year-round problems in greenhouse vegetable and ornamental plant production. A short generation time and high fecundity result in enormous reproductive potential during a growing season. Chemical control is often ineffective, because this is one of the aphid species in which insecticide resistance is most widespread and severe (Devonshire, 1987). An environmentally sound alternative to insecticides is the use of genetic plant resistance, provided that sources of resistance with high heritability are available to breeders. Plant resistance to aphids can work compatibly, even synergistically, with parasitism or predation upon these pests (Biswas and Singh, 1998; Starks et al., 1972). Unfortunately, breeding for aphid resistance in crop plants can be

Received for publication 19 May 2000. Accepted for publication 7 Aug. 2000. This research was funded by USDA-NRI grant 990-2718, the Interdisciplinary Research Training Group on Plant-Insect Interactions at the Center for Insect Science, University of Arizona, Tucson, the Southwest Consortium on Plant Genetics and Water Resources, and the United States-Israel Binational Agricultural Research and Development Fund (BARD), Grant No. IS-2129-92 and No. IS-270896. The authors thank James D. McCreight for providing seed of AR 5 and PMR 5, Michel Pitrat for providing seed of 'Margot', and Vilmorin Seed Company, France, for providing seed of 'Védrantais'. The cost of publishing this paper was defrayed in part by the payment of page charges. Under postal regulations, this paper therefore must be hereby marked advertisement solely to indicate this fact. ${ }^{1}$ Corresponding author: email gathompson@ular.edu; fax (501) 569-8020.Current address: Department of Applied Science, University of Arkansas at Little Rock, 2801 South University Ave., Little Rock, AR 72204-1099. a slow process, and is difficult by traditional selection methods. Marker assisted selection offers a means to increase the efficiency of incorporating aphid resistance in new plant varieties.

Genetic plant resistance to A. gossypii has been identified in several sources of melon (Cucumis melo) germplasm and was found to be conditioned by a major dominant gene in two of these sources, PI 371795, a momordica variety from India, from which PI 414723 was derived (Kishaba et al., 1971; McCreight et al., 1992), and PI 161375, a chinensis variety from Korea (Pitrat and Lecoq, 1980). Bohn et al. (1972) identified three categories of resistance to A. gossypii in the Indian accession: plant tolerance, antixenosis (nonpreference), and antibiosis (reduced performance). Segregation analysis indicated that antibiosis is conditioned by a major dominant gene in the Indian source of resistance (Kishaba et al., 1976), and that antixenosis and antibiosis are controlled by the same locus (Pitrat and Lecoq, 1982). Interestingly, aphid resistance derived from both the Indian and the Korean accessions was found to be tightly linked, or possibly allelic, to a gene conferring resistance to transmission of nonpersistent viruses by A. gossypii (Pitrat and Lecoq, 1980; Romanow et al., 1986). The genetic locus controlling antibiosis, antixenosis, and virus transmission resistance in PI 414723 was designated Vat (virus aphid transmission) by Pitrat and Lecoq (1982). These authors asserted that aphid resistance in the Korean accession, PI 161375, is also conditioned by Vat, although no evidence of allelism between the Indian and Korean resistance traits has been published.

Aphid resistance has been introgressed into melon breeding lines from both sources of resistance to create several pairs of nearly isogenic lines (NILs) (Chen et al., 1997b; McCreight et al., 1984), allowing detailed analyses of the effects of resistance on A. gossypii. Comparisons of aphid feeding behavior and performance between nearly isogenic resistant and susceptible melon lines have indicated that the resistance mechanism was associated 
with the phloem. Electronic monitoring of probing behavior was used to show that resistance in NIL AR 5 (from Indian accession PI 371795) caused prolonged salivation into sieve elements by aphids and inhibited phloem sap ingestion (Klingler et al., 1998). The same technique was used by other authors (Chen et al., 1997b) to show that resistance in NIL 'Margot' (from Korean accession PI 161375) also inhibited phloem sap ingestion, although no alteration of aphid salivation into sieve elements was observed. In the latter study, the authors also reported that phloem sap exudate from the resistant NIL 'Margot' reduced aphid feeding when it was included in artificial diets, suggesting that a soluble component of the phloem sap is involved in the resistance mechanism. This finding contrasts with a study by Kennedy and Kishaba (1977), who made reciprocal grafts between resistant melon plants (derived from the Indian source) and susceptible, unrelated melon plants. The authors infested the scion and root stock of each type of graft, and never observed translocation of resistance across the graft union. This suggested that the resistance factor was not translocated in the phloem. Moreover, resistance in AR 5 was associated with larger and more numerous callose deposits at aphid feeding sites (Shinoda, 1993), raising the possibility that aphid-induced callose deposition inhibits phloem sap ingestion. Each study used only one of the resistance sources; no published studies have compared the two directly. The conflicting reports on the nature of aphid resistance derived from accessions PI 371795 and PI 161375 indicate a need to clarify the mechanism of resistance and the genetic relation between resistance derived from the two sources.

The inclusion of A. gossypii resistance on genetic maps of melon will facilitate its selection in melon breeding programs. Moreover, high-resolution mapping of the Vat locus will allow for the eventual cloning and molecular characterization of the resistance gene. Four genetic maps of melon have been published using several types of markers (Baudracco-Arnas and Pitrat, 1996; Perin et al., 1998; Pitrat, 1991; Staub et al., 1998; Wang et al., 1997). The Vat locus is included in genetic maps derived from crosses with Korean accession PI 161375, but no tightly linked markers have been reported (Baudracco-Arnas and Pitrat, 1996; Perin et al., 1998; Pitrat, 1991). No genetic map has included the locus for aphid resistance derived from Indian PI 414723. This paper presents a genetic map of the Vat locus in PI 414723, and reports evidence that Vat resides in a cluster of plant resistance genes. Supporting data are also presented that Vat is present in both the Indian and Korean sources of aphid resistance.

\section{Materials and Methods}

MaPPing POPUlation. Cucumis melo var. reticulatus 'UC Top Mark' (Zink and Gulber, 1987), designated TM, served as the susceptible parent. Breeding line 414723-4 S3 (C. melo var. momordica, designated MOM), served as the source of aphid resistance. It was derived from a single plant of PI 414723 by three self-pollinations and selection for watermelon mosaic virus resistance (Gilbert et al., 1994). (TM $\times \mathrm{MOM} \mathrm{F}_{1}$ individuals were self-pollinated, and $\mathrm{F}_{2}$ individuals were grown in the greenhouse, sampled for DNA extraction and selfed. DNA was also extracted from bulked leaf samples of $F_{3}$ families. Sixty-four $F_{3}$ families were used to evaluate linkage relations between aphid resistance and molecular markers.

NEARLY ISOGENIC LINES. DNA from a pair of nearly isogenic melon breeding lines, AR 5 and PMR 5, was also tested with molecular markers. Breeding line AR 5 has aphid resistance derived from Indian accession PI 371795 (progenitor of PI 414723 , the aphid-resistant parent in the mapping population). The pedigree of AR 5 includes eight successive backcrosses to aphid-susceptible breeding line PMR 5 (var. reticulatus), followed by four to six selfing generations (McCreight et al., 1984). Seeds of AR 5 used in this study were produced after at least two additional selfing generations, and were homozygous for aphid resistance.

APHIDS. Aphis gossypii used for resistance testing were taken from a colony maintained on highly susceptible green fleshed honeydew melon plants (C. melo var. inodorus) grown at $23{ }^{\circ} \mathrm{C}$ with a 16-h photoperiod.

RESistanCE TESTING OF $F_{3}$ FAMILIES. Testing of aphid resistance was conducted in a greenhouse under natural lighting, with average daily temperatures maintained between 20 and $25^{\circ} \mathrm{C}$. Sixty-four $\mathrm{F}_{3}$ families from the mapping population were tested for aphid resistance to determine the genotype of each $\mathrm{F}_{2}$ plant. Sixteen members of each family were tested, with seven new families infested simultaneously in each round of testing. As a control, every round also included eight to 10 plants each of the parental lines, MOM and TM. Plants were arranged in trays in a completely randomized design. The fourth or fifth true leaf of each plant was infested with three winged adult $A$. gossypii, confined in a 2-cm-diameter leaf cage. The next day, the adults and all but three newly deposited nymphs were removed from each leaf. The cohort of three nymphs remained confined to the leaf cage in which they were born, and after $9 \mathrm{~d}$ (slightly less than two aphid generations) the total number of aphids in each cage was counted. Plants were scored as susceptible if the number of aphids was greater than the midparent mean, or scored as resistant if the number was below this mean. At the time of counting, tissue from noninfested leaves of each $\mathrm{F}_{3}$ plant was removed and lyophilized for DNA extraction. Before DNA extraction, an equal weight of dried leaf tissue from each $\mathrm{F}_{3}$ family member was bulked to reassemble the allelic composition of the family's $F_{2}$ parent.

RFLP AND RAPD ANALYSES. DNA was prepared from pooled melon leaves according to Baudracco-Arnas (1995). Genomic DNA (3 to $5 \mu \mathrm{g}$ ) was digested with either EcoRI, HindIII, XbaI, EcoRV,DraI, or $M v a \mathrm{I}$, electrophoresed in $0.8 \%$ agarose gels, and blotted to charged nylon membranes (Genescreen Plus, Du Pont, Wilmington, Del.) using the alkaline blotting method (Ausubel et al., 1987). Hybridization was performed at $55^{\circ} \mathrm{C}$ in $6 \%$ polyethylene glycol, $5 \%$ sodium dodecyl sulfate (SDS), $5 \times$ standard saline phosphate EDTA buffer (SSPE) and $50 \mu \mathrm{g} \cdot \mathrm{mL}^{-1}$ denatured salmon sperm DNA. DNA probes, amplified by polymerase chain reaction (PCR) from the pBluescript (Stratagene, La Jolla, Calif.) vector using the T7 and M13-reverse flanking primers, were labeled by the random hexamer method (Roche Molecular Biochemicals, Indianapolis, Ind). Following hybridization, blots were washed at $55^{\circ} \mathrm{C}$ with $1 \times$ standard saline citrate buffer (SSC), $1 \%$ SDS for $20 \mathrm{~min}$, then for $3 \times 20 \mathrm{~min}$ in $0.5 \times \mathrm{SSC}, 0.5 \% \mathrm{SDS}$. Blots were stripped for repeated use by incubation in a large volume of boiling $0.1 \%$ SDS while shaking gently and cooling to room temperature for $20 \mathrm{~min}$. Some restriction fragment length polymorphism (RFLP) probes consisted of randomly selected cDNA clones from cucumber (Cucumis sativus L.) floral bud libraries (Perl-Treves et al., 1998). Other RFLP probes used in this study are homologs of the nucleotide binding site-leucine rich repeat (NBS-LRR) superfamily of plant resistance genes. These sequences were amplified by polymerase chain reaction (PCR) from melon genomic DNA with degenerate oligonucle- 
otide primers (Klingler, 1999). For automated sequencing, an ABI sequencer and the Taq DyeDeoxy Terminator Cycle sequencing kit (both from Perkin-Elmer, Norwalk, Conn.) were used. Homology searches were conducted using the Bioccellerator package (manufactured by Compugen Ltd., Petach-Tikva, Israel). Randomly amplified polymorphic DNA (RAPD) reactions were performed using random decamer sets (Operon Technologies, Alameda, Calif., and University of British Columbia, Vancouver), according to Williams et al. (1990). Amplification products were separated by electrophoresis in $1.5 \%$ Tris-borateEDTA-agarose gels, stained with ethidium bromide, and visualized under ultraviolet light. For bulked segregant analysis, DNA from 6 homozygous resistant $\mathrm{F}_{2}$ individuals (or bulked DNA of the descendant $\mathrm{F}_{3}$ family) or 15 homozygous susceptible plants were mixed to produce the resistant or susceptible DNA mixes. These were screened with 72 primers known to produce polymorphism between the TM and MOM parental lines (Silberstein et al., 1999) to identify markers that distinguish the bulks. Such markers were then analyzed in the mapping population using DNA samples of individual plants to verify the linkage. Genetic distances were measured using the MAPMAKER software (Lander et al., 1987). Linkage relations and genetic distances used in the construction of the map were based upon LOD scores $>3$, the conventional level of statistical significance in genetic mapping.

TEST OF ALLELISM BETWEEN THE INDIAN AND KOREAN SOURCES OF RESISTANCE. AR 5, an aphid-resistant melon NIL derived from Indian accession PI371795, and 'Margot', an aphid-resistant NIL (var. cantalupensis) derived from Korean accession PI 161375 (M. Pitrat, personal communication), were crossed to produce an $\mathrm{F}_{1}$ generation. An individual (AR $5 \mathrm{x}$ 'Margot') $\mathrm{F}_{1}$ plant was used to pollinate the aphid-susceptible NIL PMR 5 (the recurrent parent used to create AR 5). Seeds from this cross were grown to test for aphid resistance in a greenhouse. Two rounds of resistance testing were performed on a total of 92 progeny plants from the cross PMR 5 x (AR 5 x 'Margot') $F_{1}$. Both rounds of testing also included five plants each of AR 5, PMR 5, 'Margot', 'Védrantais' (the susceptible recurrent parent used to create 'Margot'), and (AR $5 x$ 'Margot') $F_{1}$. In the first round, 49 plants were tested as described for the $\mathrm{F}_{3}$ families. In the second round, 43 plants were tested by infesting one leaf of each plant with a caged cohort of three 3-d-old nymphs; after $7 \mathrm{~d}$, the total number of aphids in each leaf cage was counted.

\section{Results}

INHERITANCE OF APHID RESISTANCE. In each round of resistance testing, at $9 \mathrm{~d}$ after infestation aphids were significantly more abundant on leaves of susceptible genotype 'Top Mark' (TM), compared to resistant genotype PI414723 (MOM). Figure 1 shows a scattergram of aphid populations on individual plants in a typical round of $\mathrm{F}_{3}$ phenotyping. TM plants had an average of 140 aphids per leaf ( $\mathrm{SE}=5.9)$, while MOM plants had an average of 19 aphids per leaf $(\mathrm{SE}=5.0)$. Aphids reared on the two genotypes also differed markedly in appearance; those on TM were large and dark green while those on MOM were generally smaller and paler in color. $F_{1}$ plants showed aphid numbers statistically equivalent to numbers on plants of resistant parent MOM, illustrating the complete dominance of the aphid resistance trait (data not presented). Individual melon plants of each $F_{3}$ family supported levels of aphid reproduction that were similar to those on either the resistant parent or the susceptible parent. Some families were homogeneous, with all individuals resembling one of the parents, suggesting that the family descended from a homozygous $\mathrm{F}_{2}$ individual. The other families included both resistant and susceptible plants in proportions consistent with a 3 resistant : 1 susceptible ratio, indicating they descended from a heterozygous $\mathrm{F}_{2}$ progenitor. In a few cases the distribution of aphid numbers within a family gave an ambiguous result, possibly caused by occasional cool night temperatures that could have altered aphid fecundity. In such cases, new members of these families were included in later rounds of testing to clarify resistance phenotypes. Table 1 summarizes the results of the $\mathrm{F}_{3}$ family testing and shows chi-square tests of the $\mathrm{F}_{2}$ genotypic and phenotypic segregation ratios. There was a deficiency of homozygous resistant $\mathrm{F}_{2}$ parents, although the phenotypic ratio of 45 resistant : 19 susceptible plants was consistent with the expected 3 resistant : 1 susceptible segregation ratio for a dominant monogenic trait.

LinKage OF MOLECUlAR MARKERS TO Vat. Aphid resistance was tested in $64 \mathrm{~F}_{3}$ families to map the trait with respect to a set of RFLP, RAPD, and inter-SSR markers. These molecular markers had been assigned linkage relations within the melon genome using an $\mathrm{F}_{2}$ segregating population derived from a cross between PI414723 and 'Top Mark' (Perl-Treves, Kovalski, and Silberstein, unpublished). In addition to aphid resistance, this mapping population also segregated for potyvirus and powdery mildew (Sphaerotheca fuliginea Schlecht. ex Fr.) resistance genes. A linkage map of Vat and six molecular markers is shown in Fig. 2.

The molecular marker with the tightest linkage to Vat was RFLP marker NBS-2. Probe NBS-2 is homologous to the nucleotide binding site-leucine-rich repeat (NBS-LRR) superfamily

Fig. 1. Scattergram of aphid populations on individual plants in a typical round of $\mathrm{F}_{3}$ phenotyping. Each point represents the total number of aphids counted inside a leaf cage after $9 \mathrm{~d}$. The inferred resistance genotype for each $\mathrm{F}_{3}$ family's $\mathrm{F}_{2}$ parent is indicated above the corresponding set of data points. The dotted horizontal line indicates the midpoint between the mean values of the parental lines.

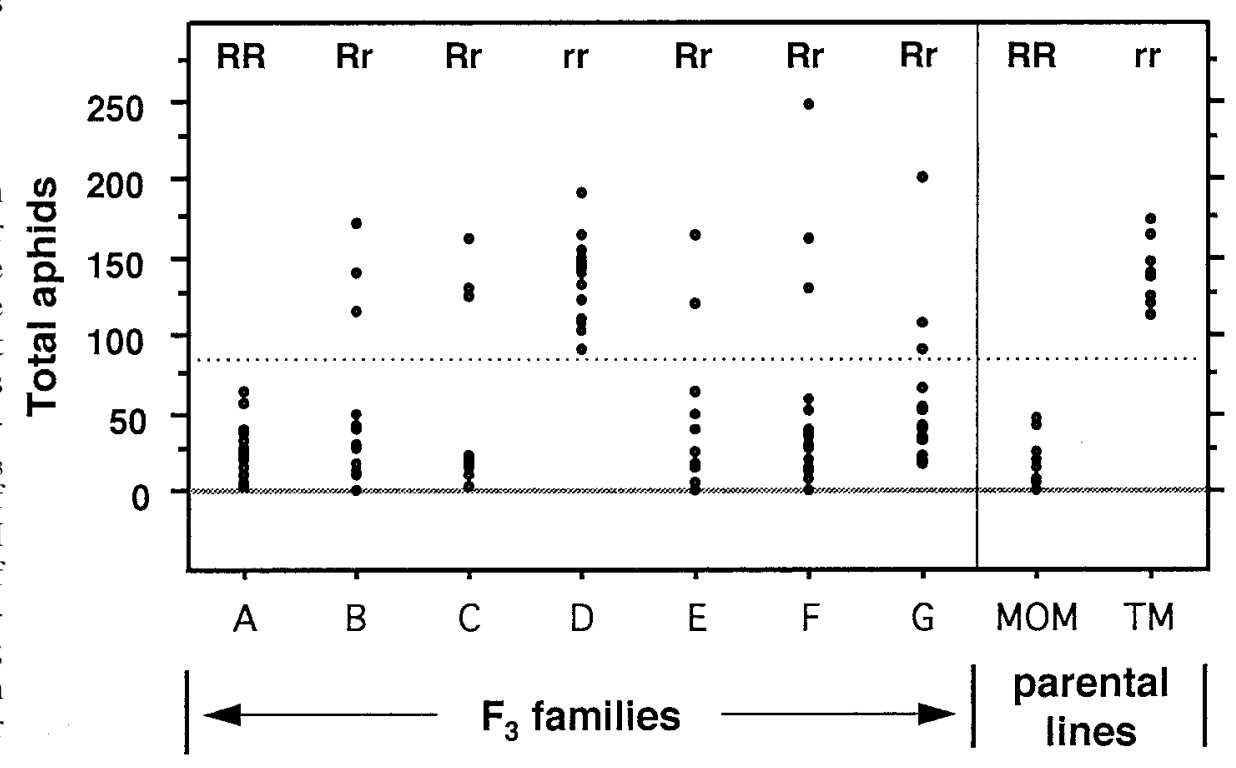


Table 1. Results of $\mathrm{F}_{3}$ family testing for aphid resistance.

\begin{tabular}{|c|c|c|c|c|c|}
\hline Genotype & \multicolumn{2}{|c|}{$\mathrm{F}_{2}$ Genotype } & & \multicolumn{2}{|c|}{$\mathrm{F}_{2}$ Phenotype } \\
\hline RR & 7 & 16 & Resistant & 45 & 48 \\
\hline $\mathrm{rr}$ & 19 & 16 & Susceptible & 19 & 16 \\
\hline \multirow[t]{2}{*}{ Chi-square } & 6.750 & & & 0.375 & \\
\hline & $\mathrm{P}_{2} \mathrm{df}=0.034$ & & & $\mathrm{P}_{1} \mathrm{df}=0.387$ & \\
\hline
\end{tabular}

of plant resistance genes. Two polymorphic EcoRV fragments segregated as a codominant marker and showed linkage with the Vat locus at a distance of $3.1 \mathrm{cM}$ (Fig. 3, top panel). The 506-base pair sequence of NBS-2 has significant amino acid similarity to the NBS coding region of several known resistance genes, including the $\mathrm{M}$ gene for rust resistance in Linum usitatissimum $\mathrm{L}$. (GenBank accession AAB47618; 38\% amino acid identity) and the $\mathrm{N}$ gene for tobacco mosaic virus resistance in Nicotiana glutinosa L. (GenBank accession A54810; 30\% amino acid identity). A second probe homologous to the NBS-LRR superfamily, NBS-5, also detected a molecular polymorphism that cosegregated with aphid resistance. RFLP marker NBS-5 was positioned at $\approx 16.8 \mathrm{cM}$ from Vat.

Two RFLP markers were detected by hybridization with probes from a cDNA library of cucumber floral buds. These markers, AC-8 and AC-39, were linked to either side of Vat, at distances of $\approx 5.5 \mathrm{cM}$ and $6.4 \mathrm{cM}$, respectively. Probe AC-8 hybridized to several restriction fragments from both parental genotypes, indicating a gene family of related sequences (Fig. 3, middle panel); two polymorphic EcoRV fragments segregated as a codominant marker and showed linkage with the Vat locus. Sequence analysis of the AC- $8 \mathrm{cDNA}$ ends revealed similarity to plant lipoxygenases (LOX), e.g., to lox4 of soybean [Glycine max (L.) Merrill]. (GenBank accession P38417) and to loxB of bean (Phaseolus vulgaris L.) (GenBank accession P27481). The 2-kb partial cDNA clone encodes $\approx 700$ amino acids out of the $\approx 850$ residues present in a LOX protein. These carboxy terminal amino acids share $39 \%$ amino acid identity and $47 \%$ similarity with LOX-encoding fragments found within the $C f-4 / C f-9$ Cladosporium fulvum (Cooke) resistance locus of tomato (Lycopersicon esculentum Mill.) (Parniske et al., 1997). Probe AC-39 hybridized to a single DraI fragment yielding a codominant polymorphism that was linked to Vat (Fig. 3, bottom panel). The AC-39 cDNA consists of a 348-bp sequence without homology to any sequence in the database. A RAPD marker, A12a, also showed linkage with Vat, although less tightly.

In an effort to obtain markers closer to the gene of interest, two samples were prepared from bulked DNA that included either homozygous resistant or homozygous susceptible individuals. Bulking DNA of individuals sharing a common genotype allows a rapid screen of markers that are likely to be linked to the locus that differentiates the bulks (Michelmore et al., 1991). The two DNA samples were screened with 72 RAPD primers that detected over 100 polymorphic products between the two parental lines. Out of the 72 primers, 6 detected polymorphism between the two DNA bulks. Of these, two bands proved to be linked to Vat after linkage analysis with individual DNA samples was carried out. PCR amplification with primer 387 showed four to six bands (Fig. 4). A fragment of $1100 \mathrm{bp}$ had the tightest linkage observed for these primers, $\approx 8.9 \mathrm{cM}$ from the locus.

MAPPING THE DONOR-PARENT INTROGRESSION IN NIL AR 5. The linked markers shown in Fig. 2 were also scored on a pair of NILs differing in aphid resistance, AR 5 and PMR 5. As shown in Fig. 5, resistant line AR 5 possessed the recurrent parent alleles of the two closest markers, AC-39 and 387.1100. The same was true for marker A12a, as would be expected since this marker maps further from Vat than either AC-39 or 387.1100. We can therefore conclude that the introgressed chromosome segment is smaller than the $15.3 \mathrm{cM}$ interval between 387.1100 and AC-39. Interestingly, the NILs differ in an additional RAPD band generated by the same primer, 387 (Fig. 5). However, this marker maps to a different linkage group than that containing Vat, demonstrating that some polymorphic markers between NILs can be unlinked to the gene of interest. It was not possible to map AC-8 with respect to the introgression, because both NILs carried the resistant parent allele. While this result is somewhat surprising, it may be explained by the fact that the two susceptible lines examined in this study, 'Top Mark' and PMR 5, have different ancestries and happen to be polymorphic at the AC-8 locus.

RELATION BETWEEN INDIAN AND KOREAN SOURCES OF RESISTANCE. Ninety-two progeny plants from the cross PMR $5 \times($ AR $5 \times$ 'Margot') $F_{1}$ were tested for aphid resistance. If resistance in AR 5

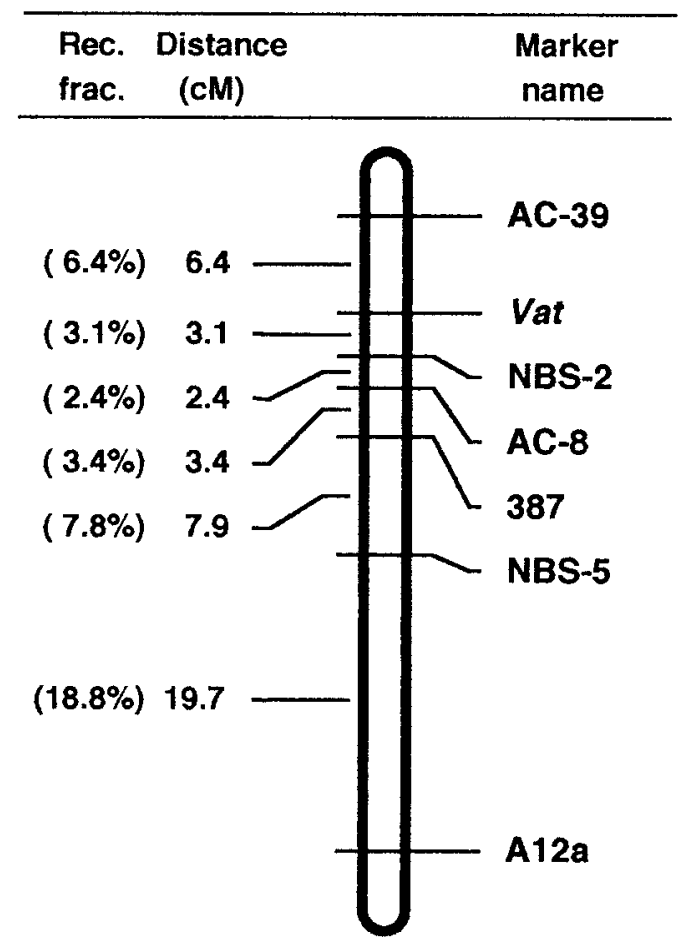

Fig. 2. Linkage map of the A. gossypii resistance locus, Vat, derived from Indian accession PI 414723. Recombination fractions (rec. frac. in percentages) and statistically corrected map distances (in $\mathrm{cM}$ ) are listed to the left of the linkage map. RFLP markers (NBS-2, NBS-5, AC-39, and AC-8) and RAPD markers (387 and A12a) were linked at LOD scores $>3$. 

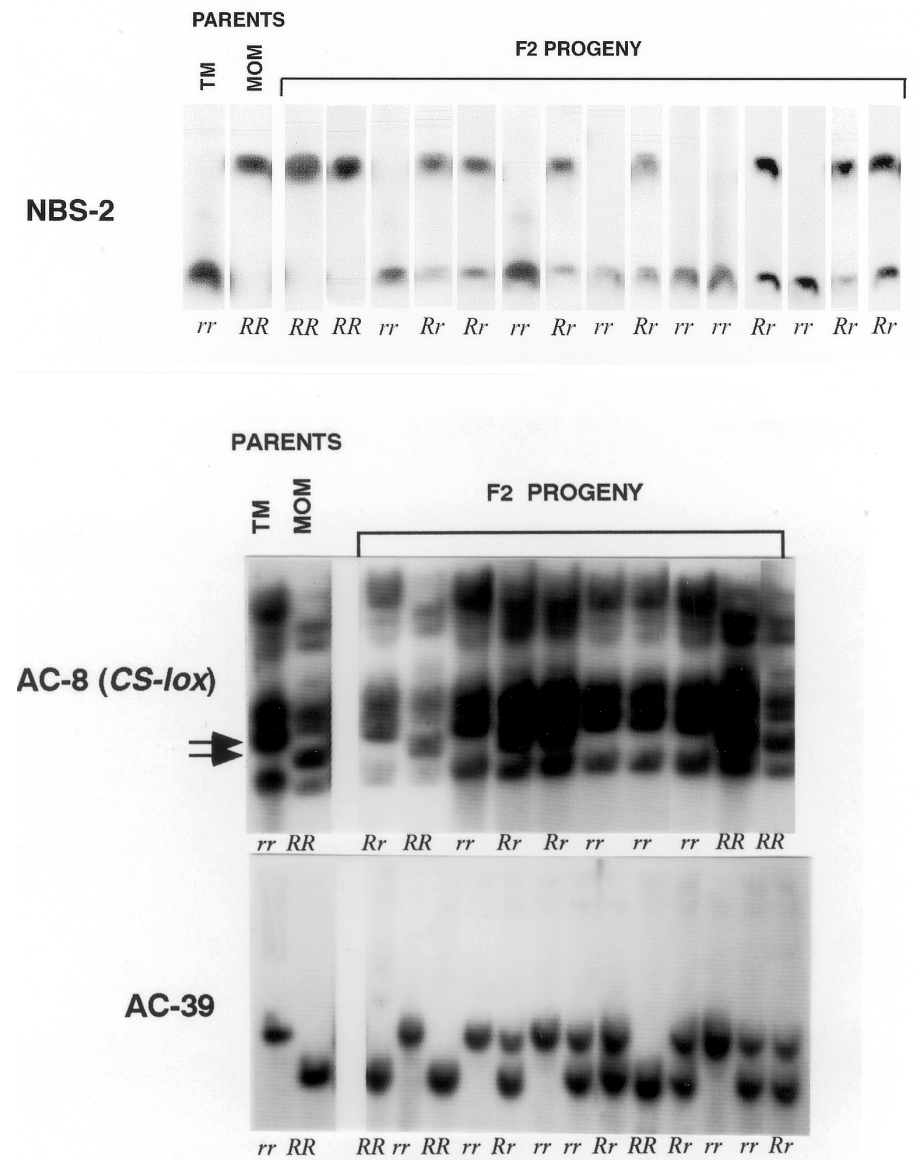

Fig. 3. RFLP analysis of genomic DNA from segregating $F_{2}$ progeny resulting from the cross 'Top Mark' x PI 414723. Genomic DNA was digested with $E c o R$ V or DraI and hybridized with genomic sequence NBS-2 (top panel; $E c o R V$ digest), cDNA AC-8 (middle panel; EcoRV digest), and cDNA AC-39 (bottom panel; DraI digest). Arrows in the middle panel indicate the two fragments with polymorphism linked to aphid resistance. Individual aphidresistance genotypes ( $R R, R r$, and $\mathrm{rr}$ ) are indicated below each lane. $\mathrm{TM}=$ 'Top Mark' (susceptible parent) and MOM=PI414723 (resistant parent). For marker $\mathrm{AC}-39$, the seventh and twelfth $\mathrm{F}_{2}$ progeny lanes from the left show recombination between the marker and the resistance genotype.

and 'Margot' were conditioned by two separate, unlinked loci, a ratio of 3 resistant: 1 susceptible progeny would be expected in this experiment. Tight linkage or allelism between the two resistance traits would lead to a low frequency or complete absence of susceptible plants in this population. We observed that 90 of the 92 progeny supported low levels of aphid reproduction similar to resistant NILs AR 5 and 'Margot'. Two plants, both in the first round of testing, had aphid numbers intermediate between the distributions for the resistant and susceptible lines (Fig. 6). Therefore, it is uncertain whether these two plants were recombinants and thus truly susceptible, or whether they were instead resistant plants. Based on our experience, these two plants were most likely resistant because the aphids were relatively small in size and scattered on the leaf surface, rather than clustered. Scattering behavior by A. gossypii has been documented as a response to resistance in the NIL AR 5 (Shinoda and Tanaka, 1989).

\section{Discussion}

Aphid resistance breeding can be complicated by the difficulty of controlling infestation levels, and by the sensitivity of aphids and host plants to environmental variation. Marker assisted selection for aphid resistance offers an efficient alternative to phenotypic selection, particularly when resistance is monogenic. To our knowledge, melon is the only crop in which monogenic resistance to $A$. gossypii has been reported. Two sources of monogenic resistance are known and well-studied: PI 371795 from India, and PI 161375 from Korea. The trait has been backcrossed from both accessions into melon breeding lines; resistance from PI 161375 is present in Charentais-type melon backgrounds (Perin et al., 1998), while resistance from PI 414723 is present in netted "Western shipper" backgrounds (McCreight et al., 1984). Although Vat (virus aphid transmission) was used originally to designate the tightly linked genes or pleiotropic gene for aphid resistance and virus transmission resistance derived from PI 371795 (Pitrat and Lecoq, 1982), all subsequent studies of aphid resistance in which the name Vat was used were based on resistance derived from PI 161375. In the present study we have developed molecular markers of potential value in marker assisted selection for aphid resistance derived from PI 371795.

We have analyzed a melon mapping population segregating for A. gossypii resistance to create a genetic map of the Vat locus. By testing $64 \mathrm{~F}_{3}$ families for aphid resistance and screening their pooled DNA for linkage with molecular markers, we identified six markers linked to the resistance trait. These include two RFLP markers, NBS-2 and AC-39, that flank Vat and define an interval of $9.5 \mathrm{cM}$. Two other genetic maps of melon have included $A$. gossypii resistance; both maps were based upon crosses using the Korean source of aphid resistance, PI 161375 (Baudracco-Arnas and Pitrat, 1996; Perin et al., 1998). The closest marker to Vat was an AFLP marker located $10 \mathrm{cM}$ away from the locus (Perin et al., 1998). In this paper, we report the first map of aphid resistance derived from the Indian accession PI 371795. RFLP marker NBS2 maps at $3.1 \mathrm{cM}$ from Vat, and may be useful in marker assisted selection for aphid resistance and resistance to virus transmission in melon breeding programs.

The linkage between Vat, resistance gene homologs NBS-2 and NBS-5, and lipoxygenase sequence AC-8, supports the hypothesis that Vat resides within a cluster of resistance gene homologs that is structurally similar to the genomic region containing the $M i, C f-2$, and $C f-5$ loci in tomato. A gene confer-

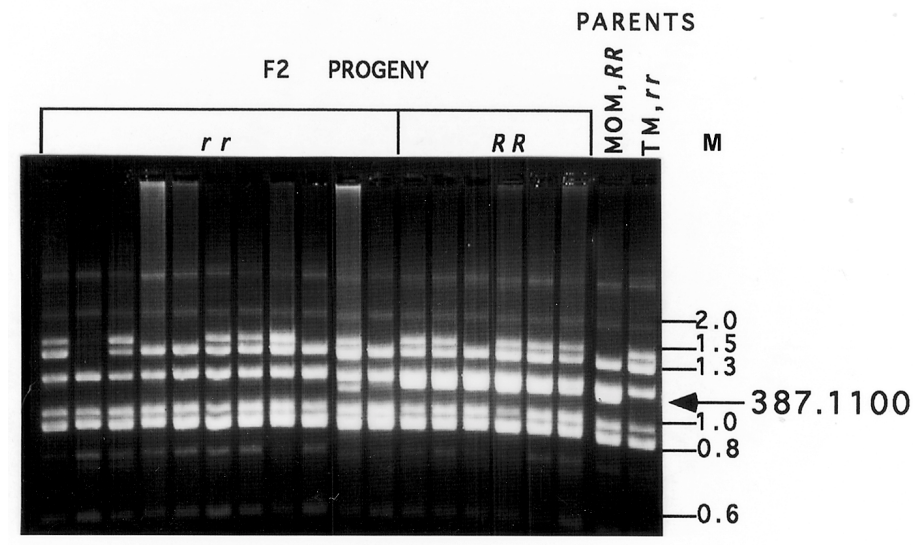

Fig. 4. RAPD analysis of the two mapping parents and a sample of $17 \mathrm{~F}_{2}$ segregating progeny using primer 387 . The ethidium bromide-stained gel shows linkage between RAPD band 387.1100 (arrow) and aphid resistance. Individual plant genotypes ( $r r$ and RR) are indicated. TM = 'Top Mark' (susceptible parent); MOM = PI 414723 (resistant parent). Molecular length markers (M) are expressed in $\mathrm{kbp}$. The tenth lane from left shows recombination between the molecular marker and the resistance genotype. 


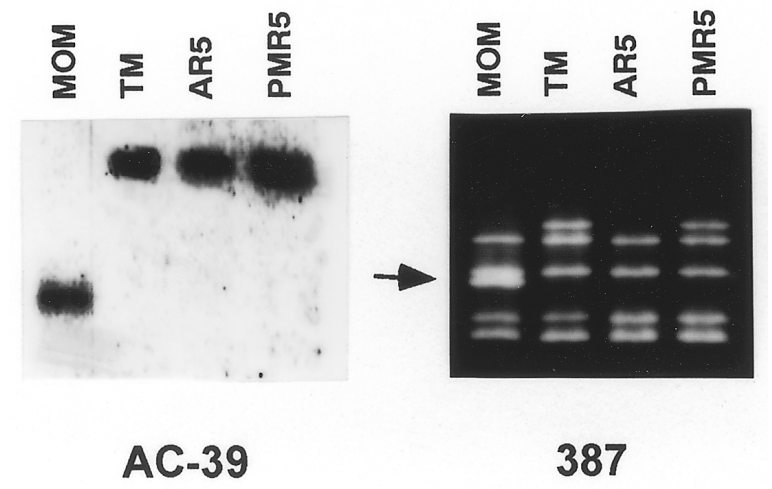

Fig. 5. Mapping of the aphid-resistance introgression from Indian accession PI 371795 in nearly isogenic line AR 5. Molecular markers flanking the resistance locus (RFLP marker AC-39, left; RAPD marker 387.1100, right, shown by arrow) show polymorphisms between the parental lines of the mapping population (MOM and TM), but are monomorphic between the NILs AR 5 (resistant) and PMR 5 (susceptible). MOM = PI 414723 (resistant); TM = 'Top Mark' (susceptible).

ring potato aphid (Macrosiphum euphorbiae Thomas) resistance and root-knot nematode (Meloidogyne sp.) resistance in tomato, $M i$, was identified recently as a member of a superfamily of plant resistance genes that have in common a putative nucleotide binding site (NBS) and a region of leucine-rich repeats (LRR) (Milligan et al., 1998; Rossi et al., 1998). Proteins encoded by NBS-LRR genes appear to link the perception of a plant pest with the activation of an appropriate plant defense (Grant and Mansfield, 1999). Members of both the NBS-LRR superfamily and the $C f$ family have been found to cluster within plant genomes (Hammond-Kosack and Jones, 1997); the Mi locus and the tightly linked $C f$-2 and $C f-5$ loci in tomato are clustered within a onemegabase region (Williamson, 1998). Lipoxygenase sequences similar to AC-8 are part of such highly diverse, rapidly evolving resistance-gene clusters of tomato (Parniske et al., 1997). Large, contiguous stretches of sequence from the $C f-4 / C f-9$ resistance gene cluster of tomato were analyzed by Parniske et al. (1977) in three haplotypes and, rather surprisingly, many individual resistance genes in the cluster were flanked by fragments of conserved lipoxygenase sequences. The discovery of resistance gene homologs and a lipoxygenase sequence near the Vat locus in melon suggests the region may harbor other genes involved in defense against pests. This hypothesis is also supported by tight linkage between Vat and powdery mildew resistance (Pitrat, 1991).

The strong correlation between aphid resistance and resistance to transmission of nonpersistent viruses by $A$. gossypii (Kishaba et al., 1992; Pitrat and Lecoq, 1980; Romanow et al., 1986;) might reflect pleiotropy of the Vat gene. However, comparisons of probing behavior by A. gossypii on nearly isogenic melon lines have provided no data supporting a causal relation between altered stylet activities induced by Vat and the inhibition of nonpersistent virus transmission. Electronic monitoring studies suggest the aphid resistance phenotype acts on aphid behavior at the level of the phloem (Chen et al., 1997b; Klingler et al., 1998), yet the transmission of nonpersistent viruses by the aphid does not require penetration of tissues deeper than the epidermis. Moreover, in an analysis of the virus transmission phenotype by the same electronic monitoring technique, transmission resistance could not be correlated with any of the Vat-induced behavioral changes in the aphid (Chen et al., 1997a). If Vat belongs to the NBS-LRR superfamily of resistance genes, its product may act on more than one signaling pathway in a manner that induces separate but parallel defense responses, one acting on the virus and another on the aphid. This model is possibly analogous to the role of the $M i$ gene in tomato, whose product has dual specificity against potato aphid and root-knot nematodes. However, if Vat lies in a resistance gene cluster, an alternative model for the correlation between aphid resistance and virus-transmission resistance is the existence of a very tight linkage between a gene acting on A. gossypii and a separate gene that inhibits virus transmission. The isolation and characterization of Vat should resolve these questions. In the event that the latter, two-gene model is verified, we propose that the gene conditioning aphid resistance be renamed Agr (Aphis gossypii resistance).

Vat in line AR 5 was introgressed from accession PI 371795 by eight successive backcrosses to PMR 5; therefore, the genomes of NILs AR 5 and PMR 5 should be highly similar. This was supported by our finding that the introgressed chromosome segment from donor parent PI 371795 is smaller than the genetic distance $(15.3 \mathrm{cM})$ between the molecular markers flanking Vat. Estimates of melon's genetic map size range from $1366 \mathrm{cM}$ (Perin et al., 1998) to $1942 \mathrm{cM}$ (Wang et al., 1997). The average of these figures can be used to estimate the size of the resistance-containing introgression, based on the method of Muehlbauer et al. (1988). The theoretical size of the donor chromosome segment in AR 5 would be $22 \mathrm{cM}$ with a standard deviation of $16 \mathrm{cM}$, assuming that no selection for recovery of the recurrent parent's morphological phenotype occurred during backcrossing. Our finding that the NILs are monomorphic for markers AC-39 and

Fig. 6. Test of allelism between aphid resistance traits in the resistant NILs AR 5 and 'Margot'. The figure shows the results of the first round of testing, involving 49 progeny plants. Each point represents the total number of aphids counted after $9 \mathrm{~d}$ inside a leaf cage placed on an individual plant. PMR 5 and 'Védrantais' are the susceptible recurrent parents used to create AR 5 and 'Margot', respectively. $\mathrm{P}=\mathrm{PMR} 5, \mathrm{~A}=\mathrm{AR} 5$, and $\mathrm{M}=$ 'Margot'.

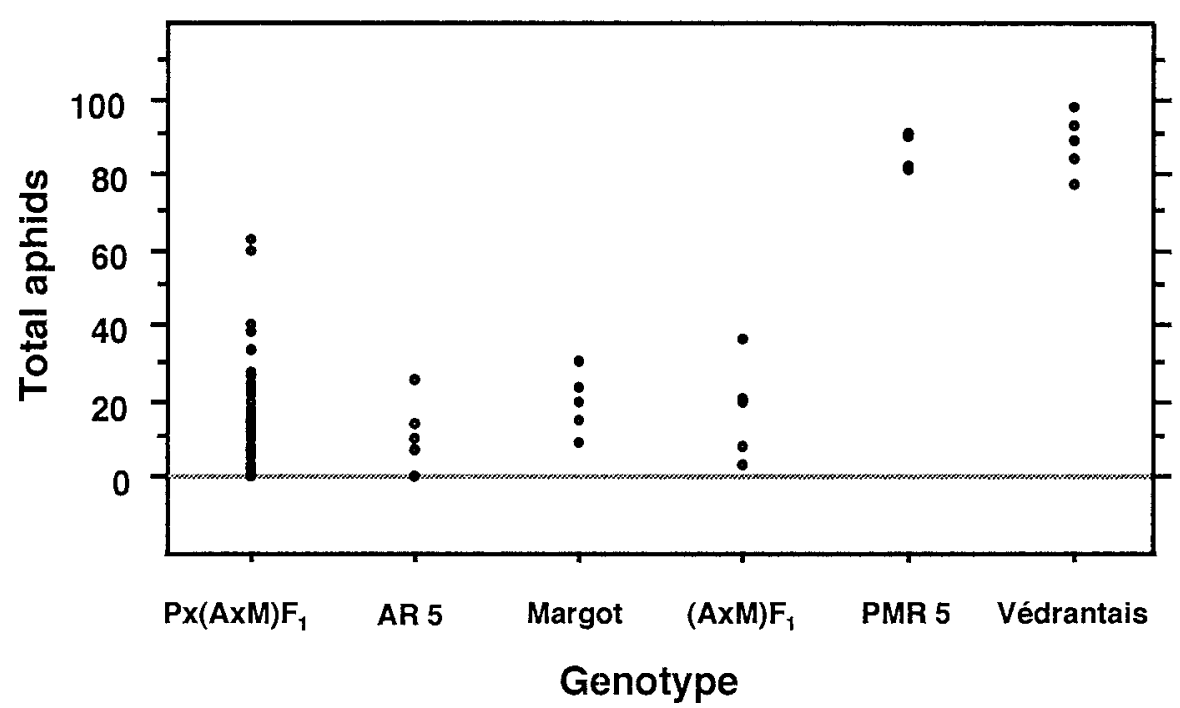


387, which flank Vat, is consistent with these estimates. In contrast, the marker closest to Vat in Fig. 2, NBS-2, does detect polymorphism between NILs AR 5 and PMR 5, and is linked to the resistance phenotype in an $\mathrm{F}_{2}$ population derived from the cross AR 5 x PMR 5 (data not presented).

Previous studies on the nature of aphid resistance in melon have given conflicting results, possibly because two separate sources of resistance have been used, Korean accession PI 161375 (Chen et al., 1997b), and Indian accession PI 371795 (Kennedy and Kishaba, 1977; Klingler et al., 1998). A major question raised by these studies pertains to whether resistance is caused by a soluble (and thus phloem mobile) factor in the sieve-tube sap. We tested for allelism between resistance from the two sources by generating a plant population from the cross PMR $5 \times($ AR $5 \times$ 'Margot') $F_{1}$. When 92 progeny from this cross were infested with aphids to determine individual plants' resistance phenotype, we observed that at least 90 progeny were resistant. If the two plants with intermediate aphid numbers were resistant, the two resistance genes may be allelic or very tightly linked. The (AR 5 x 'Margot') $F_{1}$ plants had aphid numbers similar to those on AR 5 and 'Margot'. If two separate resistance genes were present in these $F_{1}$ plants (i.e., if the resistance genes from the two germplasm sources were not allelic), then no additivity of their effects was observed. The simplest interpretation of these results is that Vat conditions aphid resistance in both the Indian-derived PI 414723 and the Korean-derived PI 161375. However, if A. gossypii resistance is conditioned by a member of a gene family that occurs in tight clusters of paralogs, as the linkage map of the Vat locus suggests (Fig. 2), then it may be difficult to establish with certainty that the same gene conditions resistance in both sources of germplasm. The ultimate clarification of this point will likely occur with cloning and molecular characterization of the Vat locus.

\section{Literature Cited}

Ausubel, F.M., R. Brent, R.E. Kingston, D.D. Moore, J.G. Seidman, J.A. Smith, and Struhl. 1987. Current protocols in molecular biology. Wiley, New York.

Baudracco-Arnas, S. 1995. A simple and inexpensive method for DNA extraction from Cucumis melo L. Cucurbit Genet. Coop. Rpt. 18:5051.

Baudracco-Arnas, S. and M. Pitrat. 1996. A genetic map of melon (Cucumis melo L.) with RFLP, RAPD, isozyme, disease resistance and morphological markers. Theor. Appl. Genet. 93:57-64.

Biswas, S. and R. Singh. 1998. Interaction between host plant resistance and the biocontrol of a cereal aphid. Biol. Agr. Hort. 16:25-36.

Blackman, R.L. and V.F. Eastop. 1984. Aphids on the world's crops: An identification guide. Wiley-Interscience, New York.

Bohn, G.W., A.N. Kishaba, and H.H. Toba. 1972. Mechanisms of resistance to melon aphid in a muskmelon line. HortScience 7:281282.

Chen J.Q., B. Martin, Y. Rahbé, and A. Fereres. 1997a. Early intracellular punctures by two aphid species on near-isogenic melon lines with and without the virus aphid transmission (Vat) resistance gene. Euro. J. Plant Pathol. 103:521-536.

Chen J.Q., Y. Rahbe, B. Delobel, N. Sauvion, J. Guillaud, and G. Febvay. 1997b. Melon resistance to the aphid Aphis gossypii-Behavioural analysis and chemical correlations with nitrogenous compounds. Entomol. Expt. Appl. 85:33-44.

Devonshire, A.L. 1987. Resistance of aphids to insecticides, p. 123-139. In: A.K. Minks and P. Harrewijn (eds.). Aphids: Their biology, natural enemies, and control. vol. 2C. Elsevier, New York.

Gilbert R.Z., M.M. Kyle, H.M. Munger, and S.M. Gray. 1994. Inheritance of resistance to watermelon mosaic virus in Cucumis melo $\mathrm{L}$.
HortScience 29:107-110.

Grant M. and J. Mansfield. 1999. Early events in host-pathogen interactions. Curr. Opin. Plant Biol. 2:312-319.

Hammond-Kosack, K.E. and J.D.G. Jones. 1997. Plant disease resistance genes. Annu. Rev. Plant Physiol. Plant. Mol. Biol. 48:575-607.

Kennedy, G.G. and A.N. Kishaba. 1977. Response of alate melon aphids to resistant and susceptible muskmelon lines. J. Econ. Entomol. 70:407410.

Kishaba, A.N., G.W. Bohn, and H.H. Toba. 1971. Resistance to Aphis gossypii in muskmelon. J. Econ. Entomol. 64:935-937.

Kishaba, A.N., G.W. Bohn, and H.H. Toba. 1976. Genetic aspects of antibiosis to Aphis gossypii in Cucumis melo from India. J. Amer. Soc. Hort. Sci. 101:557-561.

Kishaba, A.N., S.J. Castle, D.L. Coudriet, J.D. McCreight, and G.W. Bohn. 1992. Virus transmission by Aphis gossypii Glover to aphidresistant and susceptible muskmelons. J. Amer. Soc. Hort. Sci. 117:248254.

Klingler, J. 1999. Phenotypic and molecular-genetic analysis of resistance to Aphis gossypii (cotton-melon aphid) in Cucumis melo (melon). $\mathrm{PhD}$ diss. Univ. Ariz., Tucson.

Klingler, J., G. Powell, G.A. Thompson, and R. Isaacs. 1998. Phloem specific aphid resistance in Cucumis melo line AR5: Effects on feeding behaviour and performance of Aphis gossypii. Entomol. Expt. Appl. 86:79-88.

Lander, E.S., P. Green, J. Abrahamson, A. Barlow, M.J. Daly, S.E. Lincoln, and L. Newburg. 1987. MAPMAKER: An interactive computer package for constructing primary genetic linkage maps of experimental and natural populations. Genomics 1:174-181.

McCreight, J.D., G.W. Bohn, and A.N. Kishaba. 1992. Pedigree of PI414723 melon. Cucurbit Genet. Coop. Rpt. 15:51-52.

McCreight, J.D., A.N. Kishaba, and G.W. Bohn. 1984. AR Hale's Best Jumbo, AR 5, and AR Topmark: Melon aphid-resistant muskmelon breeding lines. HortScience 19:309-310.

Michelmore, R.W., I. Paran, and R.V. Kesseli. 1991. Identification of markers linked to disease-resistance genes by bulked segregant analysis: A rapid method to detect markers in specific genomic regions by using segregating populations. Proc. Natl. Acad. Sci. USA 88:98289832 .

Milligan, S.B., J. Bodeau, J. Yaghoobi, I. Kaloshian, P. Zabel, and V.M. Williamson. 1998. The root knot nematode resistance gene $M i$ from tomato is a member of the leucine zipper, nucleotide binding, leucinerich repeat family of plant genes. Plant Cell 10:1307-1319.

Muehlbauer, G.J., J.E. Specht, M.A. Thomas-Compton, P.E. Staswick, and R.L. Bernard. 1988. Near-isogenic lines-A potential resource in the integration of conventional and molecular marker linkage maps. Crop Sci. 28:729-735.

Parniske, M., K.E. Hammond-Kosack, C. Golstein, C.M. Thomas, D.A. Jones, K. Harrison, B.B.H. Wulff, and J.D.G. Jones. 1997. Novel disease resistance specificities result from sequence exchange between tandemly repeated genes at the $C f-4 / 9$ locus of tomato. Cell 91:821832.

Perin, C., L. Hagen, C. Dogimont, V. DeConto, and M. Pitrat. 1998. Construction of a genetic map of melon with molecular markers and horticultural traits, p. 370-376. In: J.D. McCreight (ed.). Evaluation and enhancement of curcurbit germplasm. Proc. Curcurbitaceae 98 Conf., Asilomar, Calif.

Perl-Treves, R., A. Kahana, N. Rosenmann, X. Yu, and L. Silberstein. 1998. Expression of multiple AGAMOUS-like genes in male and female flowers of cucumber (Cucumis sativus L.). Plant Cell Physiol. 39:701-710.

Pitrat, M. 1991. Linkage groups in Cucumis melo L. J. Hered. 82:406411.

Pitrat, M. and H. Lecoq. 1980. Inheritance of resistance to cucumber mosaic virus transmission by Aphis gossypii in Cucumis melo. Phytopathology 70:958-961.

Pitrat, M. and H. Lecoq. 1982. Relations génétiques entre les résistances par non-acceptation et par antibiose de melon Aphis gossypii. Recherche de liaisons avec d'autres gènes. Agronomie 2:503-508. 
Romanow, L.R., J.W. Moyer, and G.G. Kennedy. 1986. Alteration of efficiencies of acquisition and inoculation of watermelon mosaic virus by plant resistance to the virus and to an aphid vector. Phytopathology 76:1276-1281.

Rossi, M., F.L. Goggin, S.B. Milligan, I. Kaloshian, D.E. Ullman, and V.M. Williamson. 1998. The nematode resistance gene $M i$ of tomato confers resistance against the potato aphid. Proc. Natl. Acad. Sci. USA. 95:9750-9754.

Shinoda, T. 1993. Callose reaction induced in melon leaves by feeding of melon aphid, Aphis gossypii Glover, as possible aphid-resistant factor. Japan. J. Appl. Entomol. and Zool. 37:145-152.

Shinoda, T. and K. Tanaka. 1989. Resistance of melon Cucumis melo L. to the melon aphid, A. gossypii Glover. II. Distribution and behaviour of aphids on resistant and susceptible melon leaves. Jpn. J. Appl. Ent. Zool. 33:249-251.

Silberstein, L., I. Kovalski, R. Huang, K. Anagnostou, M.M. Kyle, and R. Perl-Treves. 1999. Molecular variation in Cucumis melo as revealed by RFLP and RAPD markers. Scientia Hort. 79:101-111.

Slosser, J.E., W.E. Pinchak, and D.R. Rummel. 1989. A review of known and potential factors affecting the population dynamics of the cotton aphid. S.W. Entomol. 14:302-313.

Starks, K.J., R. Muniappan, and R.D. Eikenbary. 1972. Interaction between plant resistance and parasitism against the greenbug on barley and sorghum. Ann. Entomol. Soc. Amer. 65:650-655.

Staub, J.E., V. Meglic, and J.D. McCreight. 1998. Inheritance and linkage relationships of melon (Cucumis melo L.) isozymes. J. Amer. Soc. Hort. Sci. 123:264-272.

Wang, Y.H., C.E. Thomas, and R.A. Dean. 1997. A genetic map of melon (Cucumis melo L.) based on amplified fragment length polymorphism (AFLP) markers. Theor. Appl. Genet. 95: 791-798.

Williams, J.G.K., A.R. Kubilek, K.I. Livak, J.A. Rafalski, and S.V. Tingey. 1990. DNA polymorphisms amplified by arbitrary primers are useful as genetic markers. Nucleic Acids Res. 18:6530-6535.

Williamson, V.M. 1998. Root-knot nematode resistance genes in tomato and their potential for future use. Annu. Rev. Phytopathol. 36:277-293.

Zink, F.W. and W.D. Gulber. 1987. U.C. PMR 45 and U.C. Top Mark fusarium wilt-resistant (Fom-3) muskmelon breeding lines. HortScience 22:172. 